\title{
Editorial
}

\section{Rapid Antibody-based Tests for the Diagnosis of COVID-19: A Bigger Epidemic of Unscientific Practices}

\author{
Sarman Singh ${ }^{1}$ \\ ${ }^{1}$ All India Institute of Medical Sciences, Bhopal, Madhya Pradesh, India \\ J Lab Physicians:2020;12:1-2
}

Coronavirus disease 2019 (COVID-19) has created havoc all over the world, and the disease has taken the lives of millions, mostly in the United States (US) and Europe. ${ }^{1}$ The virus has been claimed to originate from bats; thereafter, it passed from bats to a secondary animal before being transmitted to humans. The COVID-19 is caused by RNA virus of coronaviridae family and belongs to the $\beta$ group of Corona viruses ( $\beta-\mathrm{CoVs}$ ). The mutated SARS-Corona virus is now named SARS-CoV-2, which was discovered in Wuhan city of China from a patient afflicted with pneumonia of unknown etiology. ${ }^{2}$ Based on the rapid increase in rate of human infection, the World Health Organization (WHO) classified the disease as a pandemic. To date, more than 3.3 million cases of COVID-19 have been reported globally, with mortality recorded in 235,000 cases and the number increasing every minute. ${ }^{3}$ Within few weeks of declaring the COVID-19 a pandemic, in vitro diagnostic (IVD) assays for detection of SARS-CoV-2 were developed.

The first real-time, reverse transcription polymerase chain reaction (RT-PCR) assay with high-specificity for detection of SARS-CoV-2 RNA via envelope (E) and RNA-dependent RNA polymerase (RdRp) gene was developed in Germany in early January $2020 .{ }^{4}$ Since then, many companies have started manufacturing real-time PCR kits. Till now, the US Food and Drug Administration (FDA) has offered emergency use authorizations (EUAs) for COVID-19 diagnostic testing kits from approximately 32 manufactures/distributors. ${ }^{5}$

Due to high-demand of these kits in the US and Europe, and restrictions on international transport, it has become impossible for the Indian government to remain dependent only on imported kits in order to test its population of 1.3 billion. Even in the US and European countries, the demand of RT-PCR kits is not being met by suppliers, mainly because of lockdowns, leading to restricted production in most of these countries. In India, more than 21 domestic manufacturers have started production of RT-PCR reagents, and their concordance with standard RT-PCR Kits has ranged from as low as 10 percent to as high as 100 percent (https://www.icmr.gov.in/pdf/press_ realease_files/ICMR_Press_Release_23032020.pdf).
As the RT-PCR is technology-intensive, it has not been a favorite of small laboratories and private practitioners. Furthermore, every government, the WHO, and even the common public has been demanding testing, testing and testing. In March 2020, the FDA issued a policy to allow development of serological tests. Interestingly, more than 70 test kit developers notified the agency that they have serological tests available, and some firms have even started claiming that their serological tests are FDA-approved. ${ }^{6}$ Several other companies started manufacturing antibody-based rapid diagnostic test kits on a large scale.

As always, China was fastest in terms of development of such kits, be it rapid diagnostic tests (RDTs) for tuberculosis ${ }^{7}$ or kits for COVID-19 detection. China's Guangzhou Wondfo Biotech Co. was the first company, followed by SD Biotech of South Korea, which started mass production of these RDTs. The latter started manufacturing these RDTs in its Indian plant along with two other Indian companies. The Indian Council of Medical Research (ICMR) and Drug Controller General of India (DCGI), New Delhi, under tremendous public pressure allowed the conditional import of serological kits. (https://www.icmr.gov.in/pdf/covid/ kits/Antibody_based_tests_16042020.pdf). The ICMR and Government of India's Ministry of Health clearly notified that these RDTs will be used for surveillance purposes only and not for active case detection. This step of starting the antibody-based rapid test was met with great enthusiasm on all platforms. ${ }^{8}$

Subsequently, in the second week of April, ICMR and several state governments procured hundreds of thousands of RDTs from Wondfo Biotech and other manufactures in China and South Korea. However, within few days of this conditional import of serological kits, the Indian markets got flooded with these kits through black marketing. After field evaluation in third week of April, the ICMR found that these kits gave highly discordant results when compared with RT-PCR and also posed serious problems in their sensitivity and specificity. Realizing the backlash of poor accuracy, the

(C)2020 by The Indian Association

of Laboratory Physicians

published online

May 9, 2020
License terms

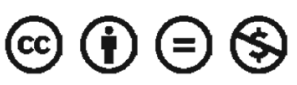

\footnotetext{
Address for correspondence

Prof. Sarman Singh, Director,

All India Institute of Medical

Sciences, Saket Nagar, Bhopal,

Madhya Pradesh, India

(e-mail: sarman_singh@yahoo.com;

sarman.singh@gmail.com).
}

DOI https://doi.org/

10.1055/s-0040-1712711

ISSN 0974-2727. 
Government of India decided in favor of rolling back the antibody-based tests and return the consignments to the manufacturers at their own cost. ${ }^{9}$

The biggest concern of using such kits is that the countries or states where these are used can lead to a false sense of low incidence in their area due to low sensitivity. The IgM and IgG antibodies which would be detected by these kits will appear only after 7 to 10 days of infection, which is known as the window period. Furthermore, during this window period, the patient will remain infectious but asymptomatic and that may result in amplification of the disease in the community. It is reported that even after 7 days of appearance of symptoms, the IgM positivity was only in $27.8 \%$ cases, IgG in only $3.3 \%$ cases, and a combination of both in $27.8 \%$ RT-PCR confirmed cases. Between 1 to 2 weeks of symptom appearance, this percentage was $48 \%, 8 \%$ and $48 \%$, while after 2 weeks, the detection rates rose to $95.8 \%, 62.5 \%$ and $95.8 \%$, respectively. ${ }^{10}$ This clearly shows that the antibody-based assays have very little diagnostic utility for COVID-19 which is a very acute disease.

The antibody-based kits for COVID-19 diagnosis also show false positive results due to longer persistence of the IgM and IgG antibodies. Due to the persistence of these antibodies even in patients who have successfully recovered from the infection, these RDTs will give false positive results. This may lead to misleading overestimation of cases in the territory, causing unrealistic phobia and panic situation. ${ }^{11}$

Therefore, these serological kits must be used for surveillance purposes only under government-controlled conditions. The sale of such kits in the open market will prove to be devastating. Many small clinics, and even patients if they get access to these tests, may go into hiding and not disclose and notify the positive results. Only molecular tests such as RT-PCR must be used for the purpose till the epidemic is over. However, there is an urgent need to upscale the capacity of molecular biology laboratories in India, especially for automated high throughput RNA extraction systems. We have by now realized that the maximum delay in reporting the results occurs on account of RNA extraction, instead of RT-PCR. Therefore, cartridge-based tests like Xpert Xpress
(Cepheid) with multiple modules or walk-away RT-PCR systems could be the only answer to meet the test demand.

\section{Conflict of Interest}

None declared.

\section{References}

1 Zheng J. SARS-CoV-2: an Emerging Coronavirus that Causes a Global Threat. Int J Biol Sci 2020;16(10):1678-1685

2 Wu Y, Ho W, Huang Y, et al. SARS-CoV-2 is an appropriate name for the new coronavirus. Lancet 2020;395(10228):949-950

3 Coronavirus Update (Live). 3,272,102 Cases and 231,321 Deaths from COVID-19 Virus Pandemic - Worldometer. Available at: https://www.worldometers.info/coronavirus/. Accessed May 4, 2020

4 Corman VM, Landt O, Kaiser M, et al. Detection of 2019 novel coronavirus (2019-nCoV) by real-time RT-PCR. Euro Surveill 2020;25(3)

5 CDC. Coronavirus Disease 2019 (COVID-19). Available at: https://www.cdc.gov/coronavirus/2019-ncov/lab/rt-pcr-panel-primer-probes.htmlAccessed May 4, 2020

6 Al-MuharraqiMA. Testing Recommendation for COVID-19 (SARS-CoV-2) in Patients Planned for Surgery - Continuing the Service and 'Suppressing' the Pandemic. Available at: https:// www.ncbi.nlm.nih.gov/pmc/articles/PMC7152878/Accessed May 4, 2020

7 Singh S, Katoch VM. Commercial serological tests for the diagnosis of active tuberculosis in India: time for introspection. Indian J Med Res 2011;134(5):583-587

8 ThackerT. India to Begin Antibody Tests to Confirm Covid19 Exposure. Economic Times. Available at: https://economictimes.indiatimes.com/industry/healthcare/biotech/ healthcare/covid-19-icmr-invites-bids-for-antibody-kitfor-virus-diagnosis/articleshow/74818887.cms? from=mdr. Accessed May 4, 2020

9 HizbullahMd, Sharma M. Testing the System: Unreliable Covid Kits Penetrate Market. Available at: https://www.indiatoday. in/india/story/india-today-tv-investigation-on-covid-19-testing-kits-in-private-markets-1672139-2020-04-28Accessed May 4, 2020

10 Imai K, Tabata S, Ikeda M, et al. Clinical evaluation of an immunochromatographic IgM/IgG antibody assay and chest computed tomography for the diagnosis of COVID-19. J Clin Virol 2020 (e-pub ahead of print) doi:10.1016/j.jcv.2020.104393

11 Petherick A. Developing antibody tests for SARS-CoV-2. Lancet 2020;395(10230):1101-1102 